\title{
SOME RESULTS ABOUT CORETRACTABLE MODULES
}

\section{Inaam Mohammed Ali Hadi University Of Baghdad College of Education (Ibn-Al-Haitham) Email: Innam1976@yahoo.com}

\author{
Shukur Neamah Al-aeashi \\ University Of Kufa \\ College of Physical Planning \\ Email: Shukur.mobred@uokufa.edu.iq
}

Recived : $12 \backslash 6 \backslash 2017$

Revised : 311712017

Accepted : $3 \backslash 8 \backslash 2017$

\begin{abstract}
Throughout this paper, all rings have identities and all modules are unitary right modules. Let $\mathrm{R}$ be a ring and $\mathrm{M}$ an $\mathrm{R}$-module. A module $\mathrm{M}$ is called coretractable if for each proper submodule $\mathrm{N}$ of $\mathrm{M}$, there exists a nonzero homomorphism $\mathrm{f}$ from $\mathrm{M} / \mathrm{N}$ into $\mathrm{M}$. Our concern in this paper is to develop basic properties of coretractable modules and to look for any relations between coretractable modules and other classes of modules.
\end{abstract}

Keyword:. coretractable modules, multiplication modules, quasi-Dedekind modules, rationallyinjective modules, prime module

Mathematics subject classification : 16D10 / 16D40 / 16L30 .

1. Introduction. The notion of coretractable module appeared in [6]. However Amini studied this notion in [4], where A module $\mathrm{M}$ is called coretractable if for each proper submodule $\mathrm{N}$ of $\mathrm{M}$, there exists a nonzero endomorphism $f$ of $M$ such that $f(N)=0$. After that many authors study some generalizations of this concept see Al-Husainy in [1] and Hadi and Al-aeashi in [10], [11], [12], [13]

and [14]. In this paper, we review coretractable modules and many of its basic properties. We give many equivalent statements for coretractable ring. Moreover we present some connections between coretractable module and other known modules such as quasi-Dedekind, multiplication, prime, quasi- injective, Kasch and rationally injective modules. Next, End(M) means ring of endomorphism on $\mathbf{M}$ and $r_{R}(M)$ means the right annihilator of $M$ in R. 


\section{§1: PRELIMINARIES}

In this section, we recall the concept of coretractability and review some known properties of coretractable modules. Also we add many new results about them and present many connections between it and other concepts. "Definition(1.1)[4]: An R-module $\mathrm{M}$ is called coretractable if for each a proper submodule $\mathrm{N}$ of $\mathrm{M}$, there exists a nonzero $\mathrm{R}$ homomorphism $\mathrm{f}: \mathrm{M} / \mathrm{N} \rightarrow \mathrm{M}$ ".

\section{Examples and Remarks (1.2):}

(1) " An R-module M is a coretractable if and only if for each proper submodule $\mathrm{N}$ of $M$ there exists a nonzero mapping $\mathrm{f} \in \operatorname{End}_{\mathrm{R}}(\mathrm{M})$ such that $\mathrm{f}(\mathrm{N})=0$; that is $\mathrm{N} \subseteq$ kerf [10],[11] ".

(2) "Clearly every semisimple module is a coretractable, and hence Every R-module over a semisimple ring is coretractable [4]" .

But it may be that coretractable module not semisimple as the $\mathrm{Z}$-module $\mathrm{Z}_{4}$.

(3) "The Pr"ufer p-group $Z_{p \infty}$ is a coretractable Z-module, since for any proper submodule $\mathrm{K}$ of $\mathrm{Z}_{\mathrm{p} \infty}, \mathrm{Z}_{\mathrm{p} \infty} / \mathrm{K} \cong \mathrm{Z}_{\mathrm{p} \infty}$ " [4].

(4) "Let $n>1$ be a positive integer. It is easy to check that the $Z$-module $Z_{n}$ is coretractable " [4].

(5) "The Z-modules Z and Q are not coretractable [14] ".

(6) "Consider $\mathrm{M}=\mathrm{Z} \oplus \mathrm{Z}_{2}$ and $\mathrm{M}=\mathrm{Z} \oplus \mathrm{Z}$ as Z-modules are not coretractable modules [14] ".

(7) "An R-module M is coretractable if and only if $\mathrm{M}$ is a coretractable $\overline{\mathrm{R}}$-module ( where $\left.\bar{R}=R / r_{R}(M)\right)[14] "$.

(8) "Coretractability is preserved by an isomorphism [14]".
(9) "An R-module $\mathrm{M}$ is coretractable if and only if $\operatorname{Hom}_{R}(M / N, M) \neq 0$ for any proper essential submodule $\mathrm{N}$ of $\mathrm{M}$ [4]" ." A submodule $\mathrm{N}$ of $\mathrm{M}$ is called an essential submodule if for any submodule $\mathrm{W}$ of $\mathrm{M}$ such that $\mathrm{N} \cap \mathrm{W}=0$, then $\mathrm{W}=0$ " [15],[9].

(10) "If $M_{1}, M_{2}, \ldots, M_{n}$ are coretractable R-modules, then so is $\bigoplus_{\mathrm{i}=1}^{\mathrm{n}} \mathrm{M}_{\mathrm{i}}$. [4, Proposition (2.6)]".

Recall that " An R-module $\mathrm{M}$ is called quasi-Dedekind if every nonzero submodule $\mathrm{N}$ of $\mathrm{M}$ is quasi-invertible where a submodule $\mathrm{N}$ of $\mathrm{M}$ is called quasi-invertible if $\operatorname{Hom}_{R}(M / N, M)=0$ " [18]. A nonzero ideal ( right ideal)I of a ring $\mathrm{R}$ is quasi-invertible ideal (right ideal)of $\mathrm{R}$ if $\mathrm{I}$ is quasi-invertible submodule of $\mathrm{R}$. Also " $\mathrm{M}$ is a quasiDedekind R-module if for any nonzero $f \in$ $\operatorname{End}_{\mathrm{R}}(\mathrm{M}), \mathrm{f}$ is a monomorphism; that is kerf= (0)" [18,Theorem(1.5), P.26].

\section{Proposition(1.3):}

(1) An R-module $\mathrm{M}$ is a coretractable if and only if every proper submodule of $\mathrm{M}$ is not quasi-invertible submodule.

Proof: It is clear.

(2) For a ring R, R is a coretractable Rmodule if and only if $r_{R}(J) \neq 0$ for each nonzero proper right ideal $\mathrm{J}$ of $\mathrm{R}$.

Proof: $\mathrm{R}$ is coretractable if and only if for all proper ideal $\mathbf{J}$ of $\mathbf{R}, \mathrm{J}$ is not quasi-invertible ideal; that is $r_{R}(J) \neq 0$ ( by [18,Proposition(2.2), P.12] )

(3) Every integral domain (not simple)is not coretractable ring. 
Proof: It is clear by Part (2)

Proposition(1.4): An R-module $M$ is coretractable quasi-Dedekind if and only if $\mathrm{M}$ is simple module.

Proof: $\Rightarrow$ Suppose there exists a proper submodule $N$ of $M, N \neq 0$. Since $M$ is quasiDedekind, $\operatorname{Hom}(\mathrm{M} / \mathrm{N}, \mathrm{M})=0$. But $\mathrm{M}$ is a coretractable module, then $\operatorname{Hom}(\mathrm{M} / \mathrm{N}, \mathrm{M}) \neq 0$ which is a contradiction. Thus $\mathrm{M}$ has no proper nonzero submodule ; and hence $\mathrm{M}$ is simple module.

$(\Leftarrow)$ It is clear.

Recall that " The submodule $Z(M)=\{m \in M$ : $r_{R}(m) \leq_{e} R$ is called the singular submodule of $M$. If $M=Z(M)$, then $M$ is called a singular module and if $\mathrm{Z}(\mathrm{M})=0$, then $\mathrm{M}$ is called a nonsingular module" [9].

Proposition(1.5): Let $M$ be an R-module. If $\mathrm{M}$ is a nonsingular uniform module, then $\mathrm{M}$ is a quasi-Dedekind, and hence $\mathrm{M}$ is not coretractable.

Proof: Let $\mathrm{N}$ be a nonzero submodule of $\mathrm{M}$, so $\mathrm{N}$ is an essential submodule of $\mathrm{M}$ ( since $\mathrm{M}$ is uniform), hence $\mathrm{M} / \mathrm{N}$ is singular. But $\mathrm{M}$ is a nonsingular. Thus $\operatorname{Hom}(\mathrm{M} / \mathrm{N}, \mathrm{M})=0$ by $[9$, Proposition(1.20), p.31]. Therefore $\mathrm{M}$ is quasi-Dedekind. Therefore $\mathrm{M}$ is not coretractable module.

\section{§2: THE MAIN RESULTS}

Recall that " A ring $\mathrm{R}$ is a right Kasch if every simple right $\mathrm{R}$-module can be embedded in $R_{R}$. Left Kasch ring" is defined similarly. As usual $\mathrm{R}$ is called a Kasch ring if it both right and left Kasch. [16,P.280] Equivalently, " $\mathrm{R}$ is a right Kasch ring if for each maximal right ideal $\mathrm{J}$ of $\mathrm{R} ; \mathrm{l}_{\mathrm{R}}(\mathrm{J}) \neq 0$ [16,Crollary(8.28),P.281]. Recall that " An R- module $M$ is called free module if $M=\bigoplus_{i \in I} R_{i}$, where $R_{i} \cong R_{R}$ for all $i \in I$ " [15].

Proposition(2.1): For a ring $\mathrm{R}$ the following statements are equivalent:

(1) $R_{R}$ is a coretractable module;

(2) $\quad l_{R}(J) \neq 0$ for each non zero proper right ideal $\mathrm{J}$ of $\mathrm{R}$; where $\mathrm{l}_{\mathrm{R}}(\mathrm{J})$ denotes the left annihilator of $\mathrm{J}$ in $\mathrm{R}$.

(3) $\mathrm{R}$ is right Kasch ring;

(4) Every finitely generated free right Rmodule is coretractable;

(5) $\quad r_{R}(J) \neq 0$ for each non zero proper right ideal $J$ of $R$; where $r_{R}(J)$ denotes the right annihilator of $\mathrm{J}$ in $\mathrm{R}$.

(6) $\operatorname{Hom}(M, R) \neq 0$ for each non zero cyclic right R-module.

Proof: $(\mathbf{1}) \Leftrightarrow(\mathbf{2}) \Leftrightarrow(3) \Leftrightarrow(4)$ It follows by [4, Theorem (2.14)].

(1) $\Leftrightarrow(\mathbf{5})$ It is clear by Proposition(1.3(2)).

$(\mathbf{5}) \Leftrightarrow(\mathbf{6})$ It follows by [3, Proposition(2.1)].

Proposition(2.2): Let $\mathrm{R}$ be a ring such that for each non zero proper right ideal I of R, $\mathrm{I}^{2}$ $=0$, then $\mathrm{R}$ is a coretractable $\mathrm{R}$-module.

Proof: Since $\mathrm{I}^{2}=0$ for all proper nonzero ideal $\mathrm{I}$ of $\mathrm{R}$, so $\mathrm{I} \subseteq \mathrm{r}_{\mathrm{R}}(\mathrm{I})$ and hence $\mathrm{r}_{\mathrm{R}}(\mathrm{I}) \neq 0$. Then $\mathrm{R}$ is a coretractable R-module by Proposition(1.3(2)).

Proposition(2.3)Let $\mathrm{R}$ be a right Kasch ring, then every nonzero ideal of $\mathrm{R}$ is coretractable. Proof: Let I be a nonzero ideal of $\mathrm{R}$. If $\mathrm{J}$ is a proper ideal of $I$, then $r_{R}(I) \subseteq r_{R}(J)$. But $r_{R}(I) \neq 0$ since $R$ is a right Kasch ring. Thus $r_{R}(J) \neq 0$. Therefore I is coretractable by Proposition(1.3(2)).

Proposition(2.4) Let $\mathrm{R}$ be a right Kasch ring, then every faithful cyclic R-module is coretractable. 
Proof: Let $M=R_{x}$ for some $x \in R$, then it is clear that $\mathrm{M} \cong \mathrm{R}_{\mathrm{x}}$. But $\mathrm{R}$ is a coretractable right $\mathrm{R}$-module, hence $\mathrm{M}$ is a coretractable $\mathrm{R}$ module.

Proposition(2.5): Let $M$ be a free finitely generated $\mathrm{R}$-module. If $\mathrm{R}$ is a right Kasch ring, then $\mathrm{M}$ is a coretractable module.

Proof: Since $M$ is a free finitely generated Rmodule, then $M=\bigoplus_{i=1}^{n} \quad R_{i} \cdot R_{i} \cong R_{R}$ for all $\mathrm{i}=1,2, \ldots, n$. But $R_{R}$ is a coretractable ring since $R$ is Kasch ring and hence $M=\bigoplus_{i=1}^{n} R_{i}$ is coretractable by Examples and Remarks(1.1(10)).

Proposition(2.6): Let $\mathrm{R}$ be a principal ideal domain. Then the following are equivalent:

(1) Every n-generated projective Rmodule is a coretractable module;

(2) The free R-module $\mathrm{R}^{\mathrm{n}}$ is coretractable.

Proof: (1) $\Rightarrow(2)$ It follows directly, since every free module is projective and hence $R^{n}$ is n-generated projective. Thus it is coretractable.

(2) $\Rightarrow(\mathbf{1})$ Let $M$ be an $n$-generated projective $\mathrm{R}$-module. Hence $\mathrm{M}$ is an $\mathrm{n}$-generated free by [20,Corollary(5.5.4)]. Hence $\mathrm{M}=\bigoplus_{\mathrm{i}=1}^{\mathrm{n}} \quad \mathrm{R}_{\mathrm{i}}$. $\mathrm{R}_{\mathrm{i}} \cong \mathrm{R}_{\mathrm{R}}$ for all $\mathrm{i}=1,2, . ., \mathrm{n}$; that is $\mathrm{M} \cong \mathrm{R}^{\mathrm{n}}$ and therefore $\mathrm{M}$ is a coretractable module.

Recall that " An R-module $\mathrm{M}$ is called multiplication module if for each submodule $\mathrm{N}$ of $\mathrm{M}$, there exists an ideal I in $\mathrm{R}$ such that $\mathrm{MI}=\mathrm{N}[5]$.

Equivalently, $\mathrm{M}$ is multiplication module if for each submodule $\mathrm{N}$ of $\mathrm{M}, \mathrm{N}=\mathrm{M}[\mathrm{N}: \mathrm{M}]$, where $[N: M]=\{r \in R: M r \subseteq N\}$ " [7] .

\section{$\operatorname{Remarks(2.7):}$}

(1) If $\mathrm{M}$ is a finitely generated multiplication coretractable R-module. Then $\mathrm{R}$ may be not coretractable. For example the
Z-module $\quad Z_{6} \quad$ is a finitely generated multiplication coretractable Z-module, but Z is not coretractable.

(2) Let $\mathrm{M}$ be a finitely generated (or multiplication) R-module. Then $\mathrm{M}$ is coretractable if and only if for each maximal submodule $\mathrm{W}$ of $\mathrm{M}$, there exists $\mathrm{f} \in \operatorname{End}_{\mathrm{R}}(\mathrm{M})$, $\mathrm{f} \neq 0$ and $\mathrm{f}(\mathrm{W})=0$.

Proof: It is clear.

Recall that " A module $\mathrm{M}$ over a commutative ring $\mathrm{R}$ is called scalar module if for all $f \in \operatorname{End}_{R}(M), f \neq 0$, there exists $0 \neq r \in$ R such that $\mathrm{f}(\mathrm{m})=\mathrm{mr}$ for each $\mathrm{m} \in \mathrm{M}$ " [22].

Proposition(2.8): Let $M$ be a faithful multiplication R-module, then $\mathrm{M}$ is coretractable module, if $\mathrm{R}$ is a commutative coretractable ring. And the converse hold if $\mathrm{M}$ is finitely generated.

Proof: Let $\mathrm{N}<\mathrm{M}$. Since $\mathrm{M}$ is a multiplication $\mathrm{R}$-module, then $\mathrm{N}=\mathrm{MI}$ for some ideal I of R. Since $R$ is coretractable ring, $r_{R}(I) \neq 0$. So there exists $t \in r_{R}(I), t \neq 0$ and hence $t \notin$ $r_{R}(M)$ since $M$ is faithful. Define $f: M \rightarrow M$ by $f(m)=m t$ for all $m \in M$. It is clear that $f$ is well-defined, also $\mathrm{f} \neq 0$ ( because if $\mathrm{f}=0$, then $f(M)=M t=0$ and hence $t \in r_{R}(M)=0$, which is a contradiction. Now, we can show that $\mathrm{f}(\mathrm{N})=0$ as follows. Let $\mathrm{x} \in \mathrm{N}$, so $0 \neq \mathrm{x}=\sum_{\mathrm{i}=1}^{\mathrm{n}} \mathrm{m}_{\mathrm{i}} \mathrm{a}_{\mathrm{i}}$ such that $\mathrm{m}_{\mathrm{i}} \in \mathrm{M}, \mathrm{a}_{\mathrm{i}} \in \mathrm{I}$ where $\mathrm{i}=1,2, \ldots, n$. Thus $\mathrm{f}(\mathrm{x})=\left(\sum_{\mathrm{i}=1}^{\mathrm{n}} \mathrm{m}_{\mathrm{i}} \mathrm{a}_{\mathrm{i}}\right) \mathrm{t}=$ $\sum_{i=1}^{n} m_{i} a_{i} t=0$ since $t \in r_{R}(I)$. Hence $f(N)=0$.

Thus $\mathrm{M}$ is a coretractable module.

Conversely, Let I < R, then N=MI < M. Since $\mathrm{M}$ is coretractable module, there exists $\mathrm{f} \in \operatorname{End}_{\mathrm{R}}(\mathrm{M}), \mathrm{f} \neq 0, \mathrm{f}(\mathrm{N})=\mathrm{f}(\mathrm{MI})=\mathrm{f}(\mathrm{M}) \mathrm{I}=0$. But $\mathrm{M}$ is finitely generated multiplication, so $\mathrm{M}$ is a scalar R-module by [22,Corollary(1.1.11)], so 
there exists $r \neq 0, r \in R$ such that $f(m)=m r$ for each meM. Thus $\mathrm{f}(\mathrm{M})=\mathrm{Mr}$ and so $0=\mathrm{f}(\mathrm{N})=\mathrm{MrJ}$. Now define $\mathrm{g}: \mathrm{R} \rightarrow \mathrm{R}$ by $\mathrm{g}(\mathrm{a})=\mathrm{ar}$ for all $\mathrm{a} \in \mathrm{R}$. Hence $\mathrm{g}(\mathrm{I})=\mathrm{Ir}$. But $\mathrm{MrI}=0$ implies rI $\subseteq$ annM $=0$; that is $\mathrm{rI}=0$. Thus $\mathrm{g}(\mathrm{I})=0$ and $\mathrm{g} \neq 0$ since $\mathrm{g}(1)=\mathrm{r} \neq 0$.

Recall that " An R-module $M$ is called prime if $r_{R}(x)=r_{R}(y)$ for each nonzero element $\mathrm{x}$ and $\mathrm{y}$ in $\mathrm{M}$ " [8]. Equivalently, " A module $\mathrm{M}$ is called prime if for every non-zero submodule $\mathrm{K}$ of $\mathrm{M}, \mathrm{r}_{\mathrm{R}}(\mathrm{K})=\mathrm{r}_{\mathrm{R}}(\mathrm{M})$ " [23].

Proposition( 2.9): Let $M$ be a multiplication R-module with $r_{R}(M)$ is a prime ideal of $R$, then $\mathrm{M}$ is a coretractable R-module if and only if $\mathrm{M}$ is semisimple $\mathrm{R}$-module.

Proof: $(\Longrightarrow)$ By Examples and Remarks(1.1 (9)) $\mathrm{M}$ is a coretractable module if and only if every proper submodule $\mathrm{N}$ of $\mathrm{M}, \mathrm{N}$ is not quasi-invertible but $\mathrm{M}$ is a multiplication $\mathrm{R}$ module with $r_{R}(M)$ is a prime ideal implies $\mathrm{N} \nless_{\mathrm{e}} \mathrm{M}$ by $[18$, Theorem3.11,P.18], so $\mathrm{M}$ has no proper essential submodule. Thus $\mathrm{M}$ is a semisimple module.

$(\Longleftarrow) \quad$ It is clear.

Corollary(2.10): Let $M$ be a prime multiplication R-module then $\mathrm{M}$ is coretractable module if and only if $\mathrm{M}$ is semisimple module.

Proof: Since $\mathrm{M}$ is prime module, then $\operatorname{ann}_{R}(\mathrm{M})$ is a prime right ideal.

Therefore, the result follows by Proposition (2.9).

Following Albu and Wisbauer, [3] " An Rmodule $\mathrm{M}$ is called Kasch module if it contain a copy of every simple R-module ", so a ring $\mathrm{R}$ is right $\mathrm{Kasch}$ ring if $\mathrm{R}$ is a right Kasch R-module; thus $\mathrm{R}$ is coretractable.

\section{Examples and Remarks(2.11):}

(1) "Kasch module which is finitely generated or quasi-injective is a coretractable module " [4].

(2) "Any semisimple module is a Kasch module " [3].

(3) " Let $\mathrm{M}$ be a nonsingular R-module then $M$ is Kasch module if and only if $M$ is semisimple " [3].In particular the Z-module $\mathrm{Z}_{\mathrm{n}}$ is a Kasch module if and only $\mathrm{Z}_{\mathrm{n}}$ is semisimple.

(4) " Let $\mathrm{R}=\mathrm{Z}$ and $\mathrm{M}=\prod_{\mathrm{p} \in \mathrm{P}} \mathrm{Zp}$, where $\mathrm{P}$ is the set of all prime numbers. Then $M$ is not a coretractable Z-module. On the other hand, $\mathrm{M}$ is a Kasch module " [4, Example (2.17(a))].

(5) " Let $\mathrm{K}$ be a field and let $\mathrm{R}$ be the ring of all matrices of the form

$\mathrm{r}=\left(\begin{array}{ccc}\mathrm{a} & \mathrm{x} & \mathrm{y} \\ 0 & \mathrm{~b} & \mathrm{z} \\ 0 & 0 & \mathrm{a}\end{array}\right)$, where $\mathrm{a}, \mathrm{b}, \mathrm{x}, \mathrm{y}, \mathrm{z} \in \mathrm{K}$

Let $M=\{r \in R: b=z=0\}$. Then $M$ is a right $R$ module with exactly two proper nonzero submodules $\mathrm{A}$ and $\mathrm{B}$, where $\mathrm{A}=\{\mathrm{r} \in \mathrm{R}: \mathrm{a}=\mathrm{b}=$ $\mathrm{z}=0\}$ and $\mathrm{B}=\{\mathrm{r} \in \mathrm{R}: \mathrm{a}=\mathrm{b}=\mathrm{x}=\mathrm{z}=0\}$ Also $\mathrm{M} / \mathrm{A} \cong \mathrm{B}=\operatorname{Soc}(\mathrm{M})$ and hence $\mathrm{M}$ is coretractable. As $\mathrm{A} / \mathrm{B}$ is a simple R-module and $\mathrm{A} / \mathrm{B} ¥ \mathrm{~B}$, we deduce that $\mathrm{M}$ is not a Kasch module" [4, Example (2.17(b))].

Recall that " A submodule $\mathrm{N}$ of $\mathrm{M}$ is called a rational submodule denoted by $\mathrm{N} r_{r}$ $\mathrm{M}$ if $\operatorname{Hom}_{\mathrm{R}}(\mathrm{V} / \mathrm{N}, \mathrm{M})=0$ for all $\mathrm{V} \leq \mathrm{M}$ such that $\mathrm{N} \subseteq \mathrm{V} \subseteq \mathrm{M}$, and $\mathrm{M}$ is called rational extension of $\mathrm{N}$. Equivalently $\mathrm{N}<_{r} \mathrm{M}$ if and only if for each $x, y \in M$ with $x \neq 0$, there exists $0 \neq r \in R$, such that $y r \in N$ and $x r \neq 0$ " [9, P.55 ]. Some authors use the name the dense submodule for rational submodule [16, P.272]. 


\section{$\operatorname{Remarks}(2.12)$ :}

(1) " Let $\mathrm{M}$ be an $\mathrm{R}$-module, If $\mathrm{N}$ is a rational submodule of $\mathrm{M}$, then $\mathrm{N}$ is quasiinvertible submodule"

$[18$,

Proposition3.3,P.14].

Proof: Let $\mathrm{N}$ be a rational submodule of $\mathrm{M}$, then $\operatorname{Hom}(\mathrm{V} / \mathrm{N}, \mathrm{M})=0$, where $\mathrm{N} \subseteq \mathrm{V} \subseteq \mathrm{M}$, so when $\mathrm{V}=\mathrm{M}$, we have $\operatorname{Hom}(\mathrm{M} / \mathrm{N}, \mathrm{M})=0$. Therefore $\mathrm{N}$ is a quasi-invertible submodule

(2) If $\mathrm{M}$ is a coretractable $\mathrm{R}$-module, then $\mathrm{M}$ has no rational submodule.

Proof: Since M is a coretractable R-module , then for all a proper submodule $\mathrm{N}$ of $\mathrm{M}, \mathrm{N}$ is not quasi-invertible submodule, so $\mathrm{N} \nless_{\mathrm{r}} \mathrm{M}$ by $\operatorname{Remarks}(2.12(1))$

It is known that " Every rational submodule is essential" [9,P.56], hence every semisimple module has no rational submodule however essential submodule may not be rational for example, consider $\mathrm{M}$ $=\mathrm{Z} / \mathrm{p}^{\mathrm{n}+1} \mathrm{Z}$ as $\mathrm{Z}$-module and $\mathrm{N}=\mathrm{pZ} / \mathrm{p}^{\mathrm{n}+1} \mathrm{Z}(\mathrm{p}$ is prime, $\mathrm{n} \geq 1$ ), then $\mathrm{N} \leq_{\mathrm{e}} \mathrm{M}$ but $\mathrm{N} \varangle_{\mathrm{r}} \mathrm{M},[16$, P.272]

However under the class of nonsingular modules the two concepts are equivalent $[9, \mathrm{P} .55]$, that is a proper submodule is essential if and only if rational submodule.

Proposition(2.13): Let $\mathrm{M}$ be a nonsingular Rmodule. Then $\mathrm{M}$ is a coretractable module if and only if $\mathrm{M}$ is semisimple module.

Proof: $(1) \Rightarrow(2)$ Suppose there exists a proper submodule $\mathrm{N}$ of $\mathrm{M}$ such that $\mathrm{N}<_{\mathrm{e}} \mathrm{M}$ so $\mathrm{N}<{ }_{\mathrm{r}} \mathrm{M}$, since $\mathrm{M}$ is nonsingular which is a contradiction with Remark(2.12(2)). Then M has no proper essential submodule. Thus $\mathrm{M}$ is semisimple module

$(\mathbf{2}) \Longrightarrow(\mathbf{1})$ It is clear.
Corollary(2.14): Let $M$ be a nonsingular Rmodule. Then the following statements are equivalent:

(1) $\mathrm{M}$ is a Kasch module;

(2) $\mathrm{M}$ is a coretractable module;

(3) $\quad \mathrm{M}$ is a semisimple module.

Proof: $\quad(1) \Leftrightarrow(3) \quad$ Follows by Remarks( 2.11(3)).

(2) $\Leftrightarrow$ (3) Follows by Proposition(2.13).

Recall that " An R-module $\mathrm{M}$ is called $\boldsymbol{\kappa}$ nonsingular module if for all $0 \neq \varphi \in \operatorname{End}_{\mathrm{R}}(\mathrm{M})$ implies $\operatorname{ker} \varphi \nless_{\mathrm{e}} \mathrm{M}$, that is for all $\varphi \in \operatorname{End}_{\mathrm{R}}(\mathrm{M}), \operatorname{ker} \varphi \leq_{\mathrm{e}} \mathrm{M}$ implies $\varphi=0$ " [21],[17].

The concept of $\kappa$-nonsingular module is appeared and studied in [2], under the name essentially quasi-Dedekind.

Examples and Remarks (2.15):

(1) "Every nonsingular module is $\kappa$ nonsingular $[2, \operatorname{Remark}(2.2 .1)]$. Hence the Zmodule $\mathrm{Z}$ is $\kappa$-nonsingular module, however $\mathrm{Z}$ is not coretractable.

(2) Every semisimple R-module is $\kappa$ nonsingular module.

(3) For a commutative ring $\mathrm{R}, \mathrm{R}$ is nonsingular if and only if $\mathrm{R}$ is $\mathrm{\kappa}$-nonsingular [2, Proposition(1.2.6)].

(4) Every prime module is $\kappa-$ nonsingular by [2,Proposition(2.1.1)]".

Proposition(2.16): Let $\mathrm{M}$ be a $\kappa$-nonsingular $\mathrm{R}$-module. Then $\mathrm{M}$ is coretractable if and only if $\mathrm{M}$ is semisimple. 
Proof: $(\Longrightarrow)$ Assume there exists a proper essential submodule $\mathrm{N}$ of $\mathrm{M}$. As $\mathrm{M}$ is coretractable module, then there exists $\varphi \in \operatorname{End}_{\mathrm{R}}(\mathrm{M}), \quad \varphi \neq 0 \quad$ with $\varphi(\mathrm{N})=0$. Hence $\mathrm{N} \subseteq \operatorname{ker} \varphi$. But $\mathrm{N}$ is an essential submodule of $M$ implies $\operatorname{ker} \varphi \leq_{\mathrm{e}} \mathrm{M}$, hence $\varphi=0$ since $\mathrm{M}$ is $\kappa$-nonsingular module, which is a contradiction. Therefore $\mathrm{M}$ has no proper essential submodule; that is $\mathrm{M}$ is semisimple. $(\Longleftarrow)$ It is clear.

Proposition(2.17): Let $\mathrm{M}$ be a multiplication $\mathrm{R}$-module, then $\mathrm{M}$ is a coretractable module if and only if for each a proper submodule $\mathrm{N}$ of $\mathrm{M}, \mathrm{M}$ is not rational extension of $\mathrm{N}$.

Proof: $(\Longrightarrow)$ Let $\mathrm{N}$ be a proper submodule of M. By Remarks(2.12(2)) M has no rational submodule, hence $\mathrm{M}$ is not rational extension of $\mathrm{N}$.

$(\Longleftarrow)$ Since $\mathrm{M}$ is a multiplication R-module and $\mathrm{M}$ is not rational extension of $\mathrm{N}$ for all proper submodule $\mathrm{N}$ of $\mathrm{M}$, then by [18,Theorem.3.9] $\mathrm{N}$ is not quasi-invertible . Thus $\mathrm{M}$ is coretractable module by Proposition(1.3).

Proposition(2.18): Let $\mathrm{M}$ be a quasi-injective $\mathrm{R}$-module, then $\mathrm{M}$ is a coretractable module if and only if $\mathrm{M}$ has no rational submodule.

Proof: $(\Longrightarrow)$ It is clear by $\operatorname{Remarks}(2.12(2))$.

$(\Longleftarrow) \quad$ Let $\mathrm{N}$ be a proper submodule of $\mathrm{M}$, then by hypothesis $\mathrm{N} \varangle_{\mathrm{r}} \mathrm{M}$. As $\mathrm{M}$ is quasiinjective, $\mathrm{N}$ is not quasi-invertible submodule by $[18$, Theorem $3.5, P .16])$; that is $\operatorname{Hom}(\mathrm{M} / \mathrm{N}, \mathrm{M}) \neq 0$ and so $\mathrm{M}$ is a coretractable module.
The following lemma was given in [18]:

"Lemma(2.19): Let $M$ be a quasi-injective R-module and $\mathrm{J}\left(\operatorname{End}_{\mathrm{R}}(\mathrm{M})\right)=0$. Then $\mathrm{N}$ is an essential submodule of $\mathrm{M}$ if and only if $\mathrm{N}$ is a quasi-invertible submodule"[18, Theorem(3.8), P.17].

Now, we introduce the following theorem:

Theorem(2.20): Let $M$ be a quasi-injective R-module and $\mathrm{J}\left(\operatorname{End}_{\mathrm{R}}(\mathrm{M})\right)=0$, then $\mathrm{M}$ is a coretractable module if and only if it is semisimple.

Proof: $(\Longrightarrow)$ Suppose there exists a proper essential submodule $\mathrm{N}$ of $\mathrm{M}$, then $\mathrm{N}$ is quasiinvertible by Lemma(2.19). So $\mathrm{N}$ is a rational submodule of M by [18,Theorem(3.5),P.16]), which is a contradiction with Remarks(2.12 (2)). Then M has no proper essential submodule; that is $\mathrm{M}$ is a semisimple module. $(\Longleftarrow)$ It is clear.

Let $\mathrm{M}$ and $\mathrm{N}$ be R-modules. Recall that " $\mathrm{M}$ is called rationally $\mathbf{N}$-injective if every R-homomorphism $\mathrm{f}: \mathrm{H} \rightarrow \mathrm{M}$ (where $\mathrm{H}$ is a submodule of $\mathrm{N}$ and $\left.\operatorname{ker}(\mathrm{f}) \leq_{\mathrm{r}} \mathrm{H}\right)$, can be extended to an R-homomorphism $\mathrm{g}: \mathrm{N} \rightarrow \mathrm{M}$. An R-module $\mathrm{M}$ is called rationally injective if it is rationally $\mathrm{N}$-injective for every $\mathrm{R}$ module N " [19, Definition(2.1.1), P.30].

\section{Examples and Remarks(2.21):}

(1) "For any R-modules M and N. The $\mathrm{R}$-module $\mathrm{M}$ is rationally $\mathrm{N}$-injective if $\mathrm{N}$ has no proper rational submodules [19].

(2) Let $\mathrm{M}=\mathrm{Z} / \mathrm{PZ}$ and $\mathrm{N}=\mathrm{Z} / \mathrm{P}^{3}$ as $\mathrm{Z}$ module where $\mathrm{P}$ is a prime number. Since N is the only nonzero rational submodule of $\mathrm{M}$ then by part(1), $\mathrm{M}$ is rationally $\mathrm{N}$-injective module " [19, Examples and Remarks (2.1.2),P.30]. 
Proposition(2.22): If $\mathrm{M}$ is a coretractable $\mathrm{R}$ module, then $\mathrm{M}$ is a rationally $\mathrm{M}$-injective module.

Proof: Since $M$ is a coretractable R-module, then $\mathrm{M}$ has no proper rational submodule by Remarks(2.12(2)). Therefore $\mathrm{M}$ is rationally M-injective module by Examples and $\operatorname{Remarks}(2.21(1))$.

The converse of Proposition(2.22) is not true in general for example;

Example(2.23): The Z-module Z is rationally $\mathrm{Z}$-injective module. Since $\mathrm{Z}$ is nonsingular so by $[19, \quad$ Proposition(2.1.6),P.33], it is rationally injective, but it is not coretractable by Examples and Remarks (1.2(5)).

\section{REFERENCES}

[1] Al-Hosainy A.M.A. and Kadhim H.A., "Co-compressible Module", International Research Journal of Scientific Findings1(6), (2014).

[2] AL-Jubory Th. Y., "Some Generalizations of Quasi-Dedekind Modules", M.Sc. Thesis, University Of Baghdad, Iraq, 2010.

[3] Albu T. and Wisbauer R., " Kasch modules", in Advances in Ring Theory ( Basel, 1997), pp. 1-16.

[4] Amini B., Ershad M. and Sharif H., " Coretractable Modules "J. Aust. Math. Soc. Ser. A,86, no.3 (2009), 289-304.

[5] Bernard A. "Multiplication Modules", Vol.71,No.1(1981),174-178.

[6] Clark J.; Lomp C.; Vanaja N.; Wisbauer R.,"Lifting Modules", Frontiers In Mathematics, Birkhäuser, 2006.
[7] Dangh N.V., Huynh D.V., Smith P.F. and Wisbauer R.,"Extending Modules", Pitman Research Notes In Mathematics Series 313, Longman, New York (1994).

[8] Desale G., Nicholson W.K., "Endoprimitive rings". J. Algebra,70 (1981), 548-560.

[9] Goodearl K.R. " Ring Theory, Nonsingular Rings and Modules ". New York,Marcel Dekker, 1976.

[10] Hadi I.M.Ali and Al-aeashi Sh. N.," Strongly Coretractable Modules and Related Concepts", Journal Of Advances In Mathematics, Vol. 12, No. 12 (2016), Pp.6881-6888.

[11] Hadi I.M.Ali and Al-aeashi Sh. N., "Strongly Coretractable Modules", Iraqi Journal of Scince, Vol.58 (2C), ( 2017), Pp.1069-1075

[12] Hadi I.M.Ali and Al-aeashi Sh. N.," $\boldsymbol{P}$ Coretractable and strongly P-coretractable Modules ", Asian Journal Of Applied sciences, vol.5 No.2 (2017), Pp.427-433.

[13] Hadi I.M.Ali and Al-aeashi Sh. N.," YCoretractable and strongly Y-coretractable Modules ", Asian Journal Of Applied sciences, vol.5 No.2 (2017), Pp.427-433.

[14] Hadi I.M.Ali and Al-aeashi Sh. N.,"

Studying Some Results about Completely

Coretractable Ring (CC-ring)", Global

Journal of Mathematics, Vol. 10, No.1(

2017), 644-647.

[15] Kasch F.,. Modules and Rings, Acad. Press, London. 1982

[16] Lam T. Y., " Lectures on Modules and Rings ", (Springer, New York, 1999). 
[17] Lee G. "Theory Of Rickart Modules",

Ph.D. Thesis, the Ohio State University, Ohio State, U.S.A (2010).

[18] Mijbass A.S., "Quasi-Dedekind Modules ", Ph.D. Thesis, University of Baghdad, Iraq, 1997.

[19] Nayef M.S., "Rational Extensions And Infectivity ", Ph.D. Thesis, University Of AlMustansiriya, Baghdad, Iraq, 2015.

[20] Pandeya B. M., Chaturvedi A. K. and Gupta A. J., "Applications Of Epi-

Retractable Modules", Bulletin Of The
Iranian Mathematical Society Vol. 38 No. 2

(2012), Pp 469-477.

[21] Rizvi S.T. and Roman C.S.. "Baer and quasi-Baer modules". Comm. Algebra, 32(1) (2004), Pp 103\{123..

[22] Shihab B. N., "Scalar Reflexive Modules" Ph.D. Thesis, University Of Baghdad, Baghdad, Iraq, 2004.

[23] Zelmanowitz J.M., "Weakly primitive rings", communication in algebra, (1981), 2345.

\section{بعض النتائج حول المقاسات المنكمشة المضادة}

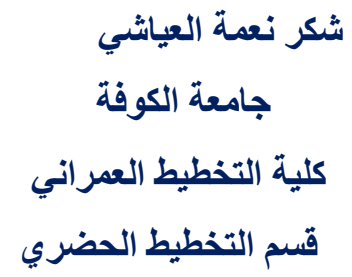

شكر نعمة العياشي

جامعة الكوفة

قسم التخطيط الحضري

المستخلص : (الم:

في هذا البحث، تم فرض جميع الحلقات بانها حلقات ذات محايد وجميع المقاسات احادية بمنى ـ لتكن R حلقة ذات محايد وM مقاساً احاديا ايمن على الحلقة R، يسمى المقاس M بانه مقاس منكمش مضاد إذا كان لكل مقاس

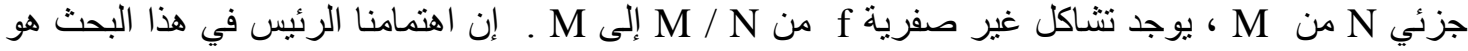
تطوير الخصائص الأساسية للمقاسات المنكمشة المضادة والبحث عن أي علاقات بين المقاسات المنكمشة المضادة و اصناف اخرى من المقاسات. 